Article

\title{
Water, Sanitation and Hygiene Conditions in Kenyan Rural Schools: Are Schools Meeting the Needs of Menstruating Girls?
}

Kelly T. Alexander ${ }^{1, *}$, Clifford Oduor ${ }^{2}$, Elizabeth Nyothach ${ }^{2}$, Kayla F. Laserson ${ }^{2,3}$, Nyaguara Amek ${ }^{2}$, Alie Eleveld ${ }^{4}$, Linda Mason ${ }^{1}$, Richard Rheingans ${ }^{5}$, Caryl Beynon ${ }^{6}$, Aisha Mohammed ${ }^{7}$, Maurice Ombok ${ }^{2}$, David Obor ${ }^{2}$, Frank Odhiambo ${ }^{2}$, Robert Quick ${ }^{8}$ and Penelope A. Phillips-Howard ${ }^{1,2}$

1 Child and Reproductive Health, Department of Clinical Studies, Liverpool School of Tropical Medicine, Liverpool L3 5QA, UK; E-Mails: linda.mason@liverpool.ac.uk (L.M.); P.Phillips-Howard@liverpool.ac.uk (P.A.P.-H.)

2 Kenya Medical Research Institute, Center for Global Health Research, Kisumu 1578-40100, Kenya; E-Mails: COduor@kemricdc.org(C.O.); ENyothach@kemricdc.org,kel4@cdc.gov (E.N.); kel4@cdc.gov (K.F.L.); NAmek@kemricdc.org (N.A.); MOmbok@kemricdc.org (M.O.); DObor@kemricdc.org (D.O.); fodhiambo@kemricdc.org (F.O.)

3 Center for Global Health, Centers for Disease Control and Prevention, Atlanta, GA 30333, USA

4 Safe Water and AIDS Project, Kisumu 40100, Kenya; E-Mail: alie@swapkenya.org

5 Department of Environmental \& Global Health and the Centre for African Studies, University of Florida, Gainesville, FL 32611, USA;

E-Mail: rrheing@epi.ufl.edu

6 Center for Public Health, Liverpool John Moores University, Liverpool L3 2ET, UK;

E-Mail: carylbeynon@hotmail.co.uk

7 Ministry of Public Health and Sanitation, Nairobi 10100, Kenya; E-Mail: a_o_mohamed@yahoo.com

8 Waterborne Diseases Prevention Branch, National Center for Emerging and Zoonotic Infectious Diseases, Centers for Disease Control and Prevention, Atlanta, GA 30333, USA;

E-Mail: rxq1@cdc.gov.org

* Author to whom correspondence should be addressed; E-Mail: kelly.alexander@liverpool.ac.uk; Tel.: +44-151-705-3784.

Received: 10 April 2014; in revised form: 9 May 2014 / Accepted: 16 May 2014 / Published: 22 May 2014

Abstract: Water, sanitation and hygiene (WASH) programs in African schools have received increased attention, particularly around the potential impact of poor menstrual 
hygiene management (MHM) on equity for girls' education. This study was conducted prior to a menstrual feasibility study in rural Kenya, to examine current WASH in primary schools and the resources available for menstruating schoolgirls. Cross-sectional surveys were performed in 62 primary schools during unannounced visits. Of these, $60 \%$ had handwashing water, $13 \%$ had washing water in latrines for menstruating girls, and $2 \%$ had soap. Latrines were structurally sound and $16 \%$ were clean. Most schools $(84 \%)$ had separate latrines for girls, but the majority (77\%) had no lock. Non-governmental organizations (NGOs) supported WASH in $76 \%$ of schools. Schools receiving WASH interventions were more likely to have: cleaner latrines (Risk Ratio (RR) 1.5; 95\% Confidence Intervals [CI] 1.0, 2.1), handwashing facilities (RR 1.6, CI 1.1, 2.5), handwashing water (RR 2.7; CI 1.4, 5.2), and water in girls' latrines (RR 4.0; CI 1.4, 11.6). Schools continue to lack essential WASH facilities for menstruating girls. While external support for school WASH interventions improved MHM quality, the impact of these contributions remains insufficient. Further support is required to meet international recommendations for healthy, gender-equitable schools.

Keywords: school; education; children; water sanitation and hygiene; NGOs; Africa; Kenya; menstruation

\section{Introduction}

Universal primary education is a Millennium Development Goal, and remains a key target for the post-2015 agenda [1]. The majority of children not enrolled in school are girls in sub-Saharan Africa, and globally $25 \%$ of students drop out of primary school before completion [2]. As schools have become a large focus of the international development agenda, increased efforts in research have attempted to describe how to maintain healthy school environments. Schools are a place of disease transmission among children and structural and educational improvements can reduce the spread of disease [3]. Water, sanitation and hygiene (WASH) interventions reduce morbidity and mortality caused by diarrheal illness [4-6] and have been associated with reduced risk of trachoma [7], ascariasis infections [8] and acute respiratory infections [9].

School absenteeism is an important proxy for both childhood disease and educational outcomes [10]. Clean drinking water in schools appears to impact student health and reduce absenteeism [11,12]. Primary school access in Kenya has improved, increasing the importance of school services [13], such as handwashing, which has been shown to reduce school absenteeism [14,15]. One study demonstrated WASH interventions in schools reduced helminth re-infection in girls and boys in rural Kenya, and before-after cross-sectional surveys found improved WASH reduced absenteeism among girls [16]. Studies in the same area found that cleanliness of school latrines reduced the odds of pupil absence [17], and that a comprehensive school WASH program may improve attendance and gender parity in primary schools [18]. Water access and good latrine conditions at school were found to be important aspects of the school environment for pre-pubescent and menstruating girls in Tanzania [19], Kenya [20,21], and South Asia [22]; however, a recent study in Malawi found no impact of school WASH conditions on 
girls' absenteeism [23]. A number of qualitative studies provide reports of the adverse impact poor WASH conditions have on girls' privacy and comfort at school [24-26] and lack of menstrual hygiene management (MHM) resources may affect girls' participation in school activities due to fear of leakage [20,27]. Current findings highlight insufficient resources are available for menstruating girls in low-income countries, however reviews indicate insufficient research to clarify the impact of improved MHM on school or health parameters [28,29]. Generally there is a lack of privacy and places to change, wash or dry (reusable) sanitary materials, difficulties properly disposing of sanitary materials, and a lack of water for washing [19,30]. The majority of current data are self-reported and no known studies quantify specifically what schools do and do not have for menstruating girls.

In June 2012, we conducted a baseline cross-sectional survey of 62 primary schools in rural western Kenya to document the current WASH facilities and MHM resources available for menstruating girls. This survey was undertaken in preparation for a Menstrual Solutions Study in primary schools in rural western Kenya. While in western countries it is unusual to have a child aged over 12 years in primary school, close to a third of girls in the 62 rural Kenyan schools surveyed were 13 years and older, with three-quarters of girls aged 14-16 years having experienced three menses [31]. The aim of the Menstrual Solutions Study was to understand the acceptability, use and safety of various menstrual solutions within the context of the school environment, and to evaluate their potential impact on adolescent schoolgirls' schooling, health and well-being. The health, educational and social effects of poor conditions for menstrual hygiene management are still unclear, and additional research is needed [27,28]. This paper examines structural WASH facilities available for menstruating girls in rural Kenyan schools to identify safety hazards and resource needs prior to implementation of MHM interventions.

\section{Materials and Methods}

\subsection{Study Site and Population}

The area under study is a site within the health and demographic surveillance system (HDSS) of the KEMRI, and CDC collaborative partnership [32]. Schools were all located in Gem District of Siaya County, a rural district in the north-western part of Nyanza Province, a few miles north of Lake Victoria, in western Kenya (Figure 1). The education system in Kenya consists of eight years of primary schooling, four years of secondary and four years of university [33]. On average nationally $83 \%$ of students attend public primary school with approximately $98 \%$ of children aged $6-16$ years enrolled in public primary school in Nyanza Province [34].

\subsection{Study Design and School Sampling}

A cross-sectional study of primary schools was conducted in one of the three sub-areas of the HDSS in Gem District. Gem was chosen due to having fewer current research projects than the other HDSS areas. In April 2012, the District Education Office compiled a list of all the 71 primary schools in the district that were also within the HDSS catchment area. The head teacher of each school was invited to an introductory meeting to discuss school-related collaborative studies. Schools that did not consent to the research either missed the introductory meeting, were a Catholic boarding school, or did not have grades 5-8 at their school, necessary for inclusion in the Menstrual Solutions Study. 
Figure 1. Area of study: Gem District in Siaya County, Nyanza Province, Kenya.
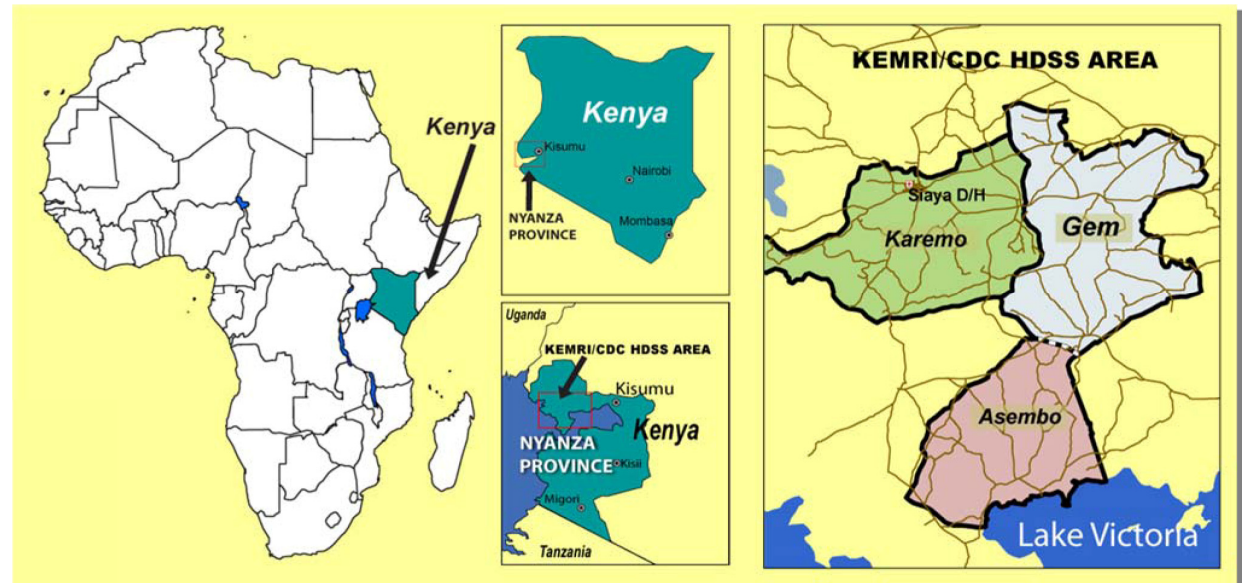

\subsection{Data Collection}

Data were captured from 62 eligible schools during unannounced visits by field staff in June 2012. Field staff with prior community expertise received a week-long training in WASH observational techniques and survey documentation using netbooks ( $2 \mathrm{go}^{\mathrm{TM}}$ Convertible Classmate PC). Survey instruments were generated after reviewing previous studies conducted in western Kenya on school WASH $[12,35,36]$. Head teachers (referred to as school respondents) provided information to the best of their knowledge on the availability of soap and water for handwashing, materials for latrine cleaning, menstrual products provided for girls, disposal of menstrual products, supply of water in girls' latrines and the infrastructure and program support received from Non-governmental organizations (NGOs). Structured observations of school facilities included presence of water and soap, privacy of girls' latrines and latrine type and conditions. Latrine conditions included record of the stability of the floor (slab), walls (holes/no holes), strong odor, a roof, door, lock on the door, and the presence of feces or pools of urine.

Concurrently, field staff aggregated data on pupil enrollment at the start of the school year from school registers. Data from paper registers, entered into netbooks by field staff, were downloaded weekly onto temporary hard drives before downloading at the KEMRI research station for incorporation into the HDSS data system.

\subsection{Definitions of Indicators}

Counts for the number of latrines used for data analysis included only those exclusively for girls and boys, excluding latrines intended for teachers and for mixed genders (there were four mixed-use latrines across all schools). Good latrine structural integrity was determined by evidence of all of the following: roof, walls with no holes, a door and stable floor slab. For latrines with good structural integrity, we additionally assessed their cleanliness (lack of strong smell, clean floor) and presence of a functional lock. Defining and agreeing on "strong smell" and "clean floor" were integral parts of the training to reduce observer bias of field staff. Latrines with structural integrity, locks and cleanliness were considered optimal conditions for student use. We categorized latrines as ventilated improved pit (VIP) latrines only if they had functioning vent pipes and screens. Schools having a private place for 
girls to wash or change were defined by having a washing or changing room specifically for girls, which at minimum comprised one girls' latrine with a lockable door. A target pupil-latrine ratio was set at 25:1 for girls and 30:1 for boys, following the Kenyan government guidelines [37].

\subsection{Data Processing and Analysis}

Data on the number of pupils, obtained from school registers from the beginning of the school year (January 2012), were aggregated by gender and class (synonymous with year as schools had no more than one class per year group). The pupil: latrine ratio per school was generated from these registry data, divided by the number of observed pupil latrines per school.

Data were analyzed in SAS 9.3 (SAS Institute Inc., Cary, NC, USA). Differences between groups were determined using Yates uncorrected $\chi^{2}$ test and the level of significance was set at 5\% or less. Mantel-Haenszel Relative Risks (RR), with Taylor Series 95\% confidence intervals (CI) were used to compare risk for various indicators with and without a specified exposure variable. Variables of interest were WASH conditions in schools; specifically for menstruating girls, and comparing those with and without NGO-supported WASH programs.

\subsection{Ethical Considerations}

Consent to conduct studies in the school was obtained from each head teacher prior to the start of unannounced WASH visits. Approval to conduct WASH and pupil attendance activities in schools within the HDSS area was received by the national ethics committee of the Kenyan Medical Research Institute (KEMRI\#1801) and the US CDC Institutional Review Boards (IRB\#3308).

\section{Results}

\subsection{General Characteristics and School Population}

The majority $(53 ; 85 \%)$ of schools were located in rural areas, with $9(15 \%)$ having houses on all sides and categorized as peri-urban. Schools are dispersed throughout the study site area, with sparse distribution in remote, hilly terrain. Across all schools, there was a median of 9 classrooms (range 5-20), 9 full-time teachers (6-21) and 3 part-time teachers (1-14). Population data were available in 60 (97\%) of the 62 schools. Across the 60 schools there was a total of 25,650 pupils, of whom 13,172 (51\%) were boys and $12,478(49 \%)$ were girls. While there were slightly more boys than girls in the upper classes (grades 5-8), differences were not significant, with a male to female ratio on average 1:1. The median pupil population in the schools was 383 (range 154-1107), with a median of 185 for girls (78-518) and 200 for boys (76-588). The median number of pupils (for both boys and girls) in classes 4, 5, 6 and 7 were similar. There was a large drop in pupil numbers in class 8 , the last class in primary school, with $35 \%$ fewer boys and $37 \%$ fewer girls, relative to class 7 .

\subsection{WASH Facilities}

There were a total of 798 sanitation facilities for students in the 62 schools surveyed (range 6-32). The majority $(590 ; 74 \%)$ were pit latrines. The remainder were VIP $(147 ; 18 \%)$, ecosan $(4 ; 0.5 \%)$ 
or urinals (57; 7\%). Urinals were predominantly for boys (53/59) with four for girls and two for teachers. Forty-two (68\%) schools had at least one urinal available for boys and three schools had a girls' urinal. Of the three schools with urinals for girls, it was noted that one school had a urinal for girls and not for boys. The number of latrines for boys was 409 (median 6, range 2-20), with 389 for girls (median 6, range 2-15).

Of 798 sanitation facilities, 563 (71\%) were in good structural condition; 181 (23\%) had locks on the doors and $126(16 \%)$ had locks and were clean. The average pupil-latrine ratio was 36:1. The average ratio was $37: 1$ for girls and 40:1 for boys. The Kenyan national target ratio for girls was met by $25(40 \%)$ schools and $28(45 \%)$ met the target ratio for boys. A quarter of schools met the target criteria for both boys and girls.

Forty-seven (75\%) schools had handwashing facilities (Table 1). The majority (73\%) of handwashing stations were located near the classrooms, while the rest were located in or near latrines. Many schools had multiple handwashing stations, with a median of two and a range of 0-10. Most handwashing facilities were a container with a tap, with tippy-taps also seen in seven (11\%) schools. Forty-one (66\%) schools had handwashing water available for pupil use as observed on the unannounced arrival of field staff. For the day surveyed, water was reported to be available by the school respondent in $44(71 \%)$ schools. Out of all schools $40(64 \%)$ respondents reported water as "always" available and $8(13 \%)$ reported it is "sometimes" available. Just under a quarter $(23 \%)$ reported "never" having water available. Out of the 62 schools visited, soap was observed next to handwashing containers in only one (2\%) school; however head teachers in six schools (10\%) reported that soap is always available. In $52(84 \%)$ schools it was reported that soap was never available. Supplies for latrine cleaning, such as disinfectant, detergent and brooms, were observed in eight (13\%) schools.

\subsection{WASH Facilities and MHM for Menstruating Girls}

Although 41 (66\%) schools had water (for handwashing), only 8 (13\%) schools were observed to have provided water in or very near the girls' latrines. Reported rates were higher with 30 (49\%) schools reporting water was "always" provided in or very near girls' latrines, 7 (11\%) "sometimes" provided, and 25 (40\%) schools "never" provided (Table 1). Fifty-two (84\%) schools had girls' latrines in a separate latrine block from boys' latrines and $20(32 \%)$ schools had a private place for girls to change. Six $(10 \%)$ school respondents reported that sanitary pads were "always" provided to girls; however these pads were given to the school by an NGO. Seventeen $(27 \%)$ schools "sometimes" provided pads and $39(63 \%)$ schools report that they were "never" able to provide pads. School respondents reported pad disposal as follows: in the latrines, 6 schools (10\%), girls carried them home, 6 schools (10\%), burned in rubbish pit, 1 school (1\%), unknown, 17 schools (27\%), no answer provided, 32 schools (52\%).

\subsection{WASH Support from Non-governmental organizations (NGOs)}

Eighteen different NGOs were reported to have worked in study schools in the past five years. Of 62 schools, 47 (76\%) reported receiving WASH support from an NGO in the form of handwashing promotion and materials, construction or rehabilitation of latrines and water sources, or any combination of the above. Schools receiving water and hygiene support (no latrine support) from an NGO were significantly more likely than schools not receiving this assistance to have: water for handwashing, 
a handwashing facility at the school, handwashing water reported as "always" available, reported providing washing water for girls, and clean latrines (Table 2). Schools receiving latrine assistance from NGOs were more likely to have VIP latrines (Table 3). No significant differences were observed for schools receiving latrine assistance from NGOs in terms of structural integrity, cleanliness or latrine: pupil ratio (Table 3).

Table 1. Schools with specific water, sanitation and hygiene (WASH) facilities, including those for menstruating girls $(n=62)$.

\begin{tabular}{lc}
\hline \multicolumn{1}{c}{ Indicator } & NBSERVED \\
\hline Girls & \\
Washing water provided for girls & \\
Girl: latrine ratio $\leq 25: 1$ & $8(13)$ \\
Private place for girls to change & $25(40)$ \\
Separate latrine block for girls & $20(32)$ \\
\hline Girls and Boys & $52(84)$ \\
Standard pupil: latrine ratio for boys and girls & \\
Latrine cleaning supplies & $16(25)$ \\
Handwashing water available & $8(13)$ \\
Handwashing facility at school & $41(66)$ \\
Soap at handwashing station & $47(75)$ \\
\hline
\end{tabular}

\section{REPORTED}

Girls

Washing water provided for girls

Always

Sometimes

Never

Sanitary pads provided at school

Always

Sometimes

Never $39(63)$

Boys and Girls

Water availability at school

Always

Sometimes

Never

Soap provided at school

Always

Sometimes

Never $52(84)$ 
Table 2. Association between WASH conditions and whether water or handwashing interventions were received from NGO.

\begin{tabular}{|c|c|c|c|c|}
\hline \multicolumn{5}{|c|}{ Schools Reported Receiving Water or Handwashing Intervention from NGO } \\
\hline \multirow{2}{*}{ Indicator } & Yes & No & & \\
\hline & $\mathrm{N}(\%)$ & $\mathrm{N}(\%)$ & $\mathrm{P}$ & $\mathrm{RR}(\mathrm{CI})$ \\
\hline OBSERVED LATRINES & $n=550$ & $n=\mathbf{2 4 8}$ & & \\
\hline Good latrine structure, lock on door and clean & $101(18)$ & $31(13)$ & $0.05 *$ & $1.5(1.0,2.1)$ \\
\hline OBSERVED SCHOOLS & $n=43$ & $n=19$ & & \\
\hline Handwashing water available for pupils & $36(84)$ & $6(32)$ & $<0.001^{*}$ & $2.7(1.4,5.2)$ \\
\hline Handwashing facility at school & $37(86)$ & $10(53)$ & $0.01 *$ & $1.6(1.1,2.5)$ \\
\hline REPORTED SCHOOLS & $n=43$ & $n=19$ & & \\
\hline Handwashing water available today & $34(79)$ & $10(53)$ & 0.07 & $1.5(1.0,2.4)$ \\
\hline Water for handwashing is "always" available & $32(74)$ & $8(42)$ & $0.03 *$ & $1.8(1.0,3.1)$ \\
\hline Washing water provided for girls & $27(63)$ & $3(16)$ & $0.001 *$ & $4.0(1.4,11.6)$ \\
\hline
\end{tabular}

Notes: * Significant at $<0.05$. P is $p$-value for Yates uncorrected $\chi^{2}$ test; RR is risk ratio; CI is $95 \%$ confidence interval. Denominator values are total schools $(n=62)$, or total latrines $(n=798)$. Schools report receiving assistance in the form of rainwater harvesting system, borehole, water tank, handwashing promotion, or containers.

Table 3. Association between latrine conditions in schools and whether latrines were provided by NGOs.

\begin{tabular}{ccccc}
\hline \multicolumn{5}{c}{ Schools Reported Receiving Latrines from NGO } \\
\hline \multirow{2}{*}{ Indicator } & Yes & No & & \\
\cline { 2 - 5 } & $\mathrm{N}(\%)$ & $\mathrm{N}(\%)$ & $\mathrm{P}$ & $\mathrm{RR}(\mathrm{CI})$ \\
\hline OBSERVED LATRINES & $\boldsymbol{n = 4 4 0}$ & $\boldsymbol{n = 3 5 8}$ & & \\
\hline Good latrine structure, no lock on door & $319(73)$ & $244(68)$ & 0.21 & $1(1.0,1.2)$ \\
Good latrine structure, lock on door & $94(21)$ & $87(24)$ & 0.37 & $0.9(0.7,1.1)$ \\
Good latrine structure, lock on door and clean & $69(16)$ & $57(16)$ & 1.00 & $1(0.7,1.3)$ \\
Ventilated Improved Pit latrines (VIP) $\dagger$ & $122(28)$ & $25(7)$ & $<0.001^{*}$ & $4.1(2.7,6.1)$ \\
\hline OBSERVED SCHOOLS & $\boldsymbol{n = 3 2}$ & $\boldsymbol{n = 2 8}$ & & \\
\hline Good pupil latrine ratio & $7(22)$ & $9(32)$ & 0.55 & $0.7(0.3,1.6)$ \\
\hline
\end{tabular}

Notes: $\mathrm{P}$ is $p$-value for Yates uncorrected $\chi^{2}$ test; RR is risk ratio; $\mathrm{CI}$ is $95 \%$ confidence interval. Denominator values are total number of latrines $(n=798)$ or total schools $(n=60)$. Two schools did not have a registry so were excluded from analysis. †VIP latrines more commonly seen compared to other types (pit, ecosan).

\section{Discussion}

This study demonstrates that the WASH conditions in the majority of rural Kenyan primary schools studied are insufficient for the MHM needs of menstruating girls. Sub-optimal WASH conditions in schools may hinder girls' ability to concentrate in class, attend school when menstruating, or at worst drop out of school completely [19,21,22,38,39]. Qualitative findings from our Menstrual Solutions Study at baseline found menstruating girls in these same rural primary schools have struggled with accessing appropriate materials for managing their menses, and require privacy in latrines and water for cleaning hands and washing due to leakage [20]. While $66 \%$ of schools provided handwashing water, only one provided soap. Handwashing with soap is generally more effective than water alone [40,41] 
and girls need soap more often during menstruation to wash soiled hands and clothes to maintain hygiene [25]. Less than half of schools met the standard pupil-latrine ratios for girls, and only one third of schools had a private, lockable place for girls to wash or change while at school. Very few schools had latrines that were in good condition, with locks and were clean. Appropriate, easy and discrete disposal of used sanitary items, an important provision for girls while at school [20,27,29] was inconsistent, unknown to head teachers, or unsustainable across study schools.

There are several possible explanations for these findings. One potential explanation may be that the government of Kenya does not provide schools with sufficient resources for constructing WASH facilities; as funds given to schools are mainly for repairing existing infrastructure [42]. Consequently, there is a dependence on NGOs for such facilities, as the schools with recent donations from NGOs were significantly more likely to have facilities. Second, maintenance of facilities is a challenge for these schools, as less than $25 \%$ of latrines had locks and only $16 \%$ were clean. One reason for poor maintenance might be because the schools do not receive enough funds from the government to cover repairs and other recurrent costs, demonstrated by the mere $13 \%$ of schools with latrine cleaning supplies. Other reasons for poor maintenance may be the lack of prioritization of WASH facilities, either because teachers have minimal awareness of their importance, because there is no monitoring or oversight of the facilities, because teachers' roles with regard to WASH are not defined, or they are overburdened and cannot take on additional responsibilities for monitoring the WASH conditions [35]. Over-reporting of actual conditions (specifically in schools with active NGO programs), may demonstrate that teachers understand the importance of maintaining water in latrines for girls and handwashing water and soap in schools, but there are inadequate resources to provide these facilities, or inadequate training on how to maintain them.

A number of studies indicate that the above water, sanitation and hygiene components are necessary for girls to feel more clean, comfortable and confident at school [19,21,25,26,38,43]; however a more rigorous understanding of how these components affect girls' participation and attendance in school is still lacking [27,28]. In spite of the lack of studies to date on the magnitude of effects poor MHM facilities have for menstruating girls; all girls deserve to have access to safe and private facilities while at school [44]. Online materials have now been developed to provide guidance on how to improve menstrual hygiene for girls in schools [25]. It is encouraging that schools with NGO WASH programs had better conditions for girls, however renewed investments in school WASH need to consider provisions which strengthen educational opportunities for girls, effective and consistent service delivery, and program sustainability to benefit all school children in the long term $[35,45,46]$. Further, evidence is accumulating on the importance of WASH to increase the likelihood of retaining girls' in schools [16,47]. It has yet to be established whether this is menstrual specific or relates to a broader need of girls safety, wellbeing and hygiene needs [20].

There are a number of limitations to this study. First, while cultural attitudes and support for girls to deal with menstrual issues is a central component of our overall Menstrual Solutions Study, data reported here covers pre-intervention activities focusing on facilities only. A separate baseline qualitative component of the Menstrual Solutions Study examined girls' needs, identifying poor preparedness for menarche, lack of proper knowledge and resources to safely and effectively manage their menstruation [20]. After baseline we addressed needs through the provision of puberty education to all eligible girls, and then allocated school nurses to all study schools to provide guidance and counseling 
to girls. Second, data were collected during one day (differing by school) and information acquired on that specific day may not necessarily represent the daily WASH conditions at each school. We minimized this bias by making unannounced visits providing the best opportunity available to document routine practice. Third, the WASH conditions as reported by head teachers were found to be less accurate than those recorded through observation as demonstrated by the poor agreement between those reporting provision of water for girls in latrines (30 schools) and those observed to have done so (8 schools). Fourth, the small school sample size (62 schools) was powered for the Menstrual Solutions Study (individual girls), which hindered our ability to examine statistical differences at the school level between all reported and observed indicators (for example, soap seen in 1 school, but reported "always" available in 6 schools). Fifth, latrine indicators were observed by field staff and there may have been slight variation in each staff's individual interpretation of conditions; however we attempted to minimize this by providing a rigorous training course which included two rounds of group piloting in (non-study) schools. The reported number of VIP latrines (versus regular pit latrines) is likely lower than might be expected due to the strict definition we set. The data we collected on NGO WASH support in the schools was not specific enough to distinguish between programs that were implemented one year ago and those that were implemented five years ago, thus limiting our ability to draw conclusions on program sustainability. Finally, for this paper we focused on the work of NGOs working in WASH, rather than more disparate measures from local government inputs which tended to be across all schools, but could have varied by school.

\section{Conclusion}

Students deserve to learn in healthy environments with access to acceptable WASH facilities. However, MHM facilities for menstruating girls in primary schools in rural Kenya are insufficient and improved access to basic resources is required. Schools with support from NGOs had better conditions overall, including for girls, than those without. Additional resources, training and monitoring in schools are needed to ensure essentials such as soap, water, and clean, private latrines are consistently available to all pupils.

\section{Acknowledgments}

We thank the head teachers, school staff, and children within schools in the health and demographic surveillance system (HDSS) in Gem District for their enthusiasm to participate in this study. Field and office staff, and the WASH team: Alex Chweya, Juliana Anyango and Paul Ogego, are thanked for their hard work and diligence. We appreciate the administrative support provided by Jiwanti Kabuka of HDSS KEMRI/CDC in Kenya, and Alison Reynolds of Liverpool School of Tropical Medicine, Liverpool, UK. The HDSS is part of the International Network for the Demographic Evaluation of Populations and Their Health in Developing Countries. We thank Thérèse Mahon of WaterAid, London, and Elizabeth von Muench of Deutsche Gesellschaft für Internationale Zusammenarbeit (GIZ) for their advice. We are grateful to John Vulule for his support. The Kenya Medical Research Institute Director approved the publication of this paper. The findings and conclusions in this paper are those of the authors and do not necessarily represent the views of the Centers for Disease Control and Prevention. 


\section{Author Contributions}

Kelly T. Alexander, Penelope A. Phillips-Howard conceptualized and drafted the paper; Elizabeth Nyothach, Frank Odhiambo, Nyaguara Amek, Maurice Ombok, oversaw data gathering and quality assurance; Kelly T. Alexander, Penelope A. Phillips-Howard, Clifford Oduor, David Obor, Frank Odhiambo, Maurice Ombok, Nyaguara Amek, processed and analyzed the data; Frank Odhiambo, Penelope A. Phillips-Howard, Linda Mason, Alie Eleveld, Richard Rheingans, Kayla F. Laserson, provided scientific leadership in developing the study research activities; Linda Mason, Caryl Beynon, Richard Rheingans, Kayla F. Laserson, provided advice on the draft manuscript; all authors have reviewed the manuscript.

\section{Conflicts of Interest}

The authors declare no conflict of interest.

\section{Disclosure}

This study is part of the preliminary phase of a proof of concept feasibility study on menstrual solutions for schoolgirls funded by the UK Medical Research Council/Department for International Development/Wellcome Trust Project Protect (G1100677/1). We received seed funding through the British Council's Prime Ministers Initiative (2) for workshops on the overlap between water and sanitation and sexual and reproductive health, supporting collaboration with UK and US universities, and local partners. Funders had no role in study design, data collection and analysis, decision to publish, or preparation of the manuscript.

\section{References}

1. United Nations. The Millennium Development Goals Report 2013; UN: New York, NY, USA, 2013.

2. Sayed, Y. Making education a priority in the post-2015 development agenda. In Report of the Global Thematic Consultation on Education in the Post-2015 Development Agenda; UNICEF: New York, NY, USA; UNESCO: Paris, France, 2013.

3. World Health Organization. Water, Sanitation and Hygiene Standards for Schools in Low-cost Settings; Adams, J., Bartram, J., Chartier, Y., Sims, J., Eds.; World Health Organization: Geneva, Switzerland, 2009.

4. Fewtrell, L.; Prüss-Üstün, A.; Bos, R.; Gore, F.; Bartram, J. Water, Sanitation and Hygiene: Quantifying the Health Impact at National and Local Levels in Countries with Incomplete Water Supply and Sanitation Coverage; WHO Environmental Burden of Disease Series No. 15; World Health Organization: Geneva, Switzerland, 2007.

5. Garrett, V.; Ogutu, P.; Mabonga, P.; Ombeki, S.; Mwaki, A.; Aluoch, G.; Phelan, M.; Quick, R.E. Diarrhoea prevention in a high-risk rural Kenyan population through point-of-use chlorination, safe water storage, sanitation, and rainwater harvesting. Epidemiol. Infect. 2008, 136, 1463-1471.

6. Cairncross, S.; Hunt, C.; Boisson, S.; Bostoen, K.; Curtis, V.; Fung, I.C.H.; Schmidt, W.P. Water, sanitation and hygiene for the prevention of diarrhoea. Int. J. Epidemiol. 2010, 39, 193-205. 
7. Montgomery, M.; Desai, M.; Elimelech, M. Assessment of latrine use and quality and association with risk of trachoma in rural Tanzania. Trans. R. Soc. Trop. Med. Hyg. 2010, 104, 283-289.

8. Fung, I.C.H.; Cairncross, S. Ascariasis and handwashing. Trans. R. Soc. Trop. Med. Hyg. 2009, 103, 215-222.

9. Patel, M.K.; Harris, J.R.; Juliao, P.; Nygren, B.; Were, V.; Kola, S.; Sadumah, I.; Faith, S.H.; Otieno, R.; Obure, A.; et al. Impact of a hygiene curriculum and the installation of simple handwashing and drinking water stations in rural Kenyan primary schools on student health and hygiene practices. Am. J. Trop. Med. Hyg. 2012, 87, 594-601.

10. Bundy, D.A.P.; Guyatt, H.L. Schools for health: Focus on health, education and the school-age child. Parasitol. Today 1996, 12, 1-14.

11. O’Reilly, C.E.; Freeman, M.C.; Ravani, M.; Migele, J.; Mwaki, A.; Ayalo, M.; Ombeki, S.; Hoekstra, R.M.; Quick, R. The impact of a school-based safe water and hygiene programme on knowledge and practices of students and their parents: Nyanza Province, western Kenya, 2006. Epidemiol. Infect. 2008, 136, 80-91.

12. Blanton, E.; Ombeki, S.; Oluoch, G.; Mwaki, A.; Wannemuehler, K.; Quick, R. Evaluation of the role of school children in the promotion of point-of-use water treatment and handwashing in schools and households-Nyanza Province, western Kenya, 2007. Am. J. Trop. Med. Hyg. 2010, $82,664-671$.

13. Halliday, K.E.; Okello, G.; Turner, E.L.; Njagi, K.; McHaro, C.; Kengo, J.; Allen, E.; Dubeck, M.M.; Jukes, M.C.H.; Brooker, S.J. Impact of intermittent screening and treatment for malaria among school children in Kenya: A cluster randomised trial. PLoS Med. 2014, 11, e1001594.

14. Bowen, A.; Ma, H.; Ou, J.; Billhimer, W.; Long, T.; Mintz, E.; Hoekstra, R.M.; Luby, S., A cluster-randomized controlled trial evaluating the effect of a handwashing-promotion program in Chinese primary schools. Am. J. Trop. Med. Hyg. 2007, 76, 1166-1173.

15. Talaat, M.; Afifi, S.; Dueger, E.; El-Ashry, N.; Marfin, A.; Kandeel, A.; Mohareb, E.; El-Sayed, N. Effects of hand hygiene campaigns on incidence of laboratory-confirmed influenza and absenteeism in schoolchildren, Cairo, Egypt. Emerg. Infect. Dis. 2011, 17, 619-625.

16. Freeman, M.C.; Greene, L.E.; Dreibelbis, R.; Saboori, S.; Muga, R.; Brumback, B.; Rheingans, R. Assessing the impact of a school-based water treatment, hygiene and sanitation programme on pupil absence in Nyanza Province, Kenya: A cluster-randomized trial. Trop. Med. Int. Health 2012, 17, 380-391.

17. Dreibelbis, R.; Greene, L.E.; Freeman, M.C.; Saboori, S.; Chase, R.P.; Rheingans, R. Water, sanitation, and primary school attendance: A multi-level assessment of determinants of household-reported absence in Kenya. Int. J. Educ. Dev. 2013, 33, 457-465.

18. Garn, J.V.; Greene, L.E.; Dreibelbis, R.; Saboori, S.; Rheingans, R.D.; Freeman, M.C. A cluster-randomized trial assessing the impact of school water, sanitation and hygiene improvements on pupil enrollment and gender parity in enrollment. J. Water Sanit. Hyg. Dev. 2013, 3, 592-601.

19. Sommer, M. Structural factors influencing menstruating school girls' health and well-being in Tanzania. Comp. J. Comp. Int. Educ. 2012, 43, 323-345. 
20. Mason, L.; Nyothach, E.; Alexander, K.; Odhiambo, F.O.; Eleveld, A.; Vulule, J.; Rheingans, R.; Laserson, K.F.; Mohammed, A.; Phillips-Howard, P.A. We keep it secret so no one should know-A qualitative study to explore young schoolgirls attitudes and experiences with menstruation in rural western Kenya. PLoS ONE 2013, 8, e79132.

21. McMahon, S.; Winch, P.; Caruso, B.; Obure, A.; Oguti, E.; Ochari, I.; Rheingans, R. The girl with her period is the one to hang her head Reflections on menstrual management among schoolgirls in rural Kenya. Int. Health Hum. Rights 2011, 11, 1-10.

22. Mahon, T.; Fernandes, M. Menstrual hygiene in South Asia: A neglected issue for WASH (water, sanitation and hygiene) programmes. Gend. Dev. 2010, 18, 99-113.

23. Grant, M.; Lloyd, C.; Mensch, B. Menstruation and school absenteeism: Evidence from rural Malawi. Comp. Educ. Rev. 2013, 57, 260-284.

24. Bolt, E.; Shordt, K.; Krukkert, I. School Sanitation and Hygiene Eduation: Results from the Assessment of a Six-country Pilot Project; UNICEF: New York, NY, USA; IRC: Delft, The Netherlands, 2006.

25. House, S.; Mahon, T.; Cavill, S. Menstrual Hygiene Matters: A Resource for Improving Menstrual Hygiene around the World; Availabl online: http://www. wateraid. org/what-wedo/our-approach/research-and-publications/view-publication?id=02309d73-8e41-4d04-b2ef6641f6616a4f\&sc_lang=en (accessed on 3 January 2014).

26. Jasper, C.; Le, T.-T.; Bartram, J. Water and sanitation in schools: A systematic review of the health and educational outcomes. Int. J. Environ. Res. Public Health 2012, 9, 2772-2787.

27. Crichton, J.; Okal, J.; Kabiru, C.W.; Zulu, E.M. Emotional and psychosocial aspects of menstrual poverty in resource-poor settings: A qualitative study of the experiences of adolescent girls in an informal settlement in Nairobi. Health Care Women Int. 2013, 34, 891-916.

28. Sumpter, C.; Torondel, B. A systematic review of the health and social effects of menstrual hygiene management. PLOS ONE 2013, 8, e62004.

29. Sommer, M.; Kjellén, M.; Pensulo, C. Girls' and women's unmet needs for menstrual hygiene management (MHM): The interactions between MHM and sanitation systems in low-income countries. Water Sanit. Hyg. Dev. 2013, doi:10.2166/washdev.2013.101.

30. Sommer, M. Ideologies of sexuality, menstruation and risk: Girls' experiences of puberty and schooling in northern Tanzania. Cult. Health Sex. 2009, 11, 383-398.

31. Phillips-Howard, P.A. Liverpool School of Tropical Medicine, Liverpool, UK. Unpublished work, 2014.

32. Odhiambo, F.O.; Laserson, K.F.; Sewe, M.; Hamel, M.J.; Feikin, D.R.; Adazu, K.; Ogwang, S.; Obor, D.; Amek, N.; Bayoh, N.; et al. Profile: The KEMRI/CDC health and demographic surveillance system-Western Kenya. Int. J. Epidemiol. 2012, 41, 977-987.

33. Omwami, E.M.; Omwami, R.K. Public investment and the goal of providing universal access to primary education by 2015 in Kenya. Int. J. Educ. Dev. 2009, 30, 243-253.

34. Mugo, J.; Kaburu, A.; Limboro, C.; Kimutai, A. Are our children learning? In Annual Learning Assessment Report; Uwezo Kenya: Nairobi, Kenya, 2012. Available online: http:/www.pokot.org/ wp-content/uploads/2012/05/Uwezo-20111.pdf (accessed on 20 November 2013). 
35. Alexander, K.T.; Dreibelbis, R.; Freeman, M.C.; Ojeny, B.; Rheingans, R. Improving service delivery of water, sanitation, and hygiene in primary schools: A cluster-randomized trial in western Kenya. J. Water Health 2013, 11, 507-519.

36. Saboori, S.; Mwaki, A.; Porter, S.E.; Okech, B.; Freeman, M.C.; Rheingans, R.D. Sustaining school hand washing and water treatment programmes: Lessons learned and to be learned. Waterlines 2011, 30, 298-311.

37. Government of Kenya. National School Health Policy; Government of Kenya: Nairobi, Kenya, 2009.

38. Sommer, M. Putting menstrual hygiene management on to the school water and sanitation agenda. Waterlines 2010, 29, 268-278.

39. Sommer, M.; Vasquez, E.; Worthington, N.; Sahin, M. WASH in schools empowers girls' education. In Proceedings of the Menstrual Hygiene Management in Schools Virtual of the Conference 2012, New York, NY,USA, 27 September 2012.

40. Luby, S.P.; Kadir, M.A.; Yushuf Sharker, M.A.; Yeasmin, F.; Unicomb, L.; Sirajul Islam, M. A community-randomised controlled trial promoting waterless hand sanitizer and handwashing with soap, Dhaka, Bangladesh. Trop. Med. Int. Health 2010, 15, 1508-1516.

41. Burton, M.; Cobb, E.; Donachie, P.; Judah, G.; Curtis, V.; Schmidt, W.-P. The effect of handwashing with water or soap on bacterial contamination of hands. Int. J. Environ. Res. Public Health 2011, 8, 97-104.

42. Gallo, K.; Mwaki, A.; Caruso, B.; Ochari, I.; Freeman, M.; Saboori, S.; Dreibelbis, R.; Rheingans, R. An Evaluation of the Financial Mangement of SWASH+ Programs in SWASH+ Primary Schools; IRC: Delft, The Netherlands, 2012; p. 14. Available online: http://www.ircwash.org/resources/evaluation-financial-management-wash-programs-swash-plusprimary-schools-swash-plus (accessed on 4 February 2014).

43. Birdthistle, I.; Dickson, K.; Freeman, M.; Javidi, L. What Impact does the Provision of Separate Toilets for Girls at Schools have on their Primary and Secondary School Enrolment, Attendance and Completion? A Systematic Review of the Evidence; EPPI-Centre, Social Science Research Unit, Institute of Education, University of London: London, UK, 2011.

44. UNICEF. Raising even more Clean Hands: Advancing Health, Learning and Equity through WASH in Schools; UNICEF: New York, NY, USA 2012.

45. Snel, M. The Worth of School Sanitation and Hygiene Education; IRC International Water and Sanitation Centre: Delft, The Netherlands, 2004.

46. IRC; UNICEF. Towards Effective Programming for WASH in Schools: A Manual for Scaling up Programmes for Water, Sanitation and Hygiene in Schools; IRC Internation Water and Sanitation Centre: Delft, The Netherlands, 2007.

47. Adukia, A. Sanitation and Education; Harvard University: Cambridge, MA, USA, 2013. Available online: http://scholar.harvard.edu/files/adukia/files/adukia_sanitation_and_education.pdf (accessed on 4 February 2014).

(C) 2014 by the authors; licensee MDPI, Basel, Switzerland. This article is an open access article distributed under the terms and conditions of the Creative Commons Attribution license (http://creativecommons.org/licenses/by/3.0/). 